\title{
Perawatan Maloklusi Klas II Divisi 1 Dentoskeletal Disertai Retrusi Mandibula Dengan Alat Fungsional Bionator
}

\author{
Afini Putri Luthfianty, Sri Suparwitri, dan Soekarsono Hardjono \\ Program Studi Ortodonsia, PPDGS, Fakultas Kedokteran Gigi, Universitas Gadjah Mada \\ JI Denta No 1 Sekip Utara, Yogyakarta, Indonesia; e-mail: afini.luthfianty@yahoo.co.uk
}

\begin{abstract}
ABSTRAK
Maloklusi klas II divisi 1 dentoskeletal disertai dengan retrusi mandibula dan lengkung rahang yang sempit dapat terjadi akibat dari faktor keturunan dan diperparah oleh kebiasaan buruk. Kondisi maloklusi tersebut ditandai dengan adanya palatal bite dan overjet yang besar. Perawatan maloklusi klas II divisi 1 pada masa pertumbuhan dan perkembangan dapat dilakukan dengan menggunakan alat ortodontik fungsional, salah satunya adalah Bionator. Pemilihan bionator bertujuan untuk menuntun rahang bawah untuk bergerak ke posisi yang diinginkan dan memperlebar lengkung rahang. Tujuan dari penulisan laporan kasus ini adalah menyajikan hasil kemajuan perawatan maloklusi klas II divisi 1 dengan menggunakan alat ortodontik fungsional Bionator. Pasien perempuan berumur 12 tahun mengeluhkan gigi depan atas maju sehingga mengganggu penampilan. Diagnosa kasus adalah maloklusi klas II divisi 1 dentoskeletal disertai dengan retrusi mandibula, bidental protrusif, palatal bite, kontraksi lengkung rahang dan malposisi gigi individual. Pasien dirawat dengan menggunakan alat ortodontik fungsional Bionator. Perawatan setelah tiga bulan, secara klinis terlihat profil pasien terkoreksi, overjet berkurang, palatal bite hilang, dan open bite posterior.
\end{abstract}

Maj Ked Gi. Desember 2014; 21(2): 212 - 216

Kata kunci: Maloklusi klas II divisi 1 dentoskeletal, Bionator

ABSTRACT: Treatment of dentoskeletal class II division I with mandibula retrussion using Bionator appliance. Malocclusion Class II division 1 dentosceletal followed with mandibular retrusion and contraction of arch could be happened by genetic and bad habit. It was showed with severe palatal bite and overjet. In the development and growth phase, the treatment for that condition is fuctional appliance, such as Bionator. Bionator arranged lower jaw to the good position and distraction the arch. The purpose of this case report is to present the treatment of malocclusion dentosceletal Class II division 1 with fuctional appliance Bionator. A 12 years old female patient complained of front upper teeth are protrusive. Diagnosis is malocclusion Class II division 1 dentosceletal followed with mandibular retrusion, bidental protrusive, palatal bite, contraction of jaw and malposition individual teeth. The patient treated with fuctional appliance Bionator. After 3 months treatment, patient's profile corrected, decreased overjet, no palatal bite, and open bite posterior. Maj Ked Gi. Desember 2014; 21(2): 212 - 216

Keywords: Malocclusion Class II division 1 dentosceletal, Bionator

\section{PENDAHULUAN}

Maloklusi Klas II divisi 1 biasanya diikuti dengan retrusi mandibula dan merupakan faktor genetik yang diperparah dengan adanya kebiasaan buruk yang berlangsung lama. Pemilihan alat ortodontik fungsional merupakan pilihan yang tepat untuk membantu meningkatkan pertumbuhan mandibula. ${ }^{1,2}$ Beberapa alat fungsional yang berguna untuk mengoreksi diskrepansi skeletal, bentuk lengkung rahang dan fungsi orofasial salah satunya adalah Bionator. ${ }^{3,4}$

Bionator dapat mengoreksi diskrepansi yang terjadi pada dentoalveolar dan skeletal. Perubahan dentoalveolar adalah retraksi dan uprigting insisivus maksila diikuti oleh proklinasi gigi insisivus bawah. Meskipun tidak ada perubahan skeletal pada maksila, peningkatan panjang mandibula juga terjadi pada pasien yang menggunakan bionator. Perubahan skeletal yang signifikan berpengaruh terhadap perubahan jaringan lunak, terutama dimensi vertikal wajah dan posisi bibir. ${ }^{5-7}$

Tujuan dari laporan kasus ini adalah memamparkan perawatan menggunakan bionator pada pasien dengan kasus masalah pertumbuhan klas II skeletal, mandibula retrognatik. Publikasi kasus ini telah mendapat persetujuan dari orang tua pasien bagi kepentingan ilmu pengetahuan. 


\section{METODE}

Seorang pasien perempuan berumur 12 tahun datang ke klinik Ortodonsia RSGM Prof. Soedomo Yogyakarta dengan keluhan gigi depan atas maju sehingga mengganggu penampilan. Hasil pemeriksaan ekstra oral menunjukkan bentuk kepala mesosefali, bentuk muka mesoprosop, profil muka cembung, sendi temporo mandibular normal, dan bibir posisi istirahat inkompeten. Pemeriksaan intra oral menunjukkan $\mathrm{OHI}$ baik, ukuran lidah sedang, lebar dan tinggi palatum sedang. Semua gigi-geligi merupakan gigi permanen. Pada saat oklusi sentrik, overjet $11,5 \mathrm{~mm}$, overbite $3,5 \mathrm{~mm}$, terdapat palatal bite, dan relasi molar Klas II. Palatal bite terjadi karena kombinasi supraoklusi gigi anterior dan infraoklusi gigi posterior (metode Thompson-Brodie).

Keterangan pada hasil foto panoramik menunjukkan adanya impaksi pada gigi 38 dan 48 (mesioangular). Berdasarkan analisa sefalometri disimpulkan bahwa hubungan skeletal klas II dengan retrusi mandibula dan bidental protrusif. Perhitungan Pont menunjukkan pertumbuhan dan perkembangan lengkung gigi ke arah lateral mengalami kontraksi. Perhitungan Korkhaus menunjukkan pertumbuhan dan perkembangan lengkung gigi ke arah anterior mengalami protraksi. Perhitungan Howes menunjukkan kurangnya lengkung gigi dan lengkung basal menampung gigigeligi.

Diagnosis kasus ini adalah Maloklusi Angle klas II divisi 1 dentoskeletal dengan retrusi mandibula dan bidental protrusif disertai dengan palatal bite, malposisi gigi individual, dengan kebiasaan buruk bernafas lewat mulut dan menggigit bibir bawah. Prognosis kasus ini baik karena pasien didukung oleh jaringan pendukung gigi yang baik, usia pasien yang masih muda, motivasi yang tinggi, status ekonomi baik, kerjasama pasien yang baik serta kondisi kesehatan pasien yang baik.

Perhitungan Pont, Korkhaus, Howes dan kesimpulan analisa sefalometri direncanakan untuk meretraksi gigi rahang atas sebesar 2,5 $\mathrm{mm}$ dan memprognasi rahang bawah sebesar $5 \mathrm{~mm}$. Rencana perawatan kasus ini adalah: 1) tahap instruksi operator kepada pasien mengenai perawatan ortodontik, 2) tahap perawatan yaitu perawatan dengan alat fungsional Bionator dan perawatan dengan plat aktif (evaluasi dan observasi hasil dari tahap I), 3) pemakaian retainer. Perawatan tahap I kasus ini adalah operator memberikan penjelasan kepada pasien tentang perawatan ortodontik, mengenai prosedur perawatan, cara perawatan, lama perawatan, cara memakai dan melepas alat, dan pasien diminta untuk menjaga kebersihan mulutnya serta menghilangkan kebiasaan buruknya seperti bernafas lewat mulut, dan menggigit bibir bawah agar tidak menghambat perawatan ortodontik.

Perawatan tahap II dilakukan pemakaian alat fungsional bionator. Pemakaian bionator dilakukan dengan memajukan mandibula dan mengkoreksi malrelasi palatal bite anterior sebesar $5 \mathrm{~mm}$ secara bertahap. Tahap pertama memajukan mandibula sebesar $2 \mathrm{~mm}$ lalu dievaluasi. Kemudian dilanjutkan dengan memajukan mandibula sebesar $3 \mathrm{~mm}$. Kemudian dievaluasi dan observasi untuk perawatan dengan plat aktif. Alat bionator terdiri atas: a. Alat RA dan RB yang bersatu, b. Gigitan anterior diberi bite plane pada gigi anterior RA dan RB, c. Gigitan posterior dibebaskan, d. Lengkung Labial (guide wire maksila) dari interdental gigi P1 RA dengan $\varnothing 0,8 \mathrm{~mm}$. e. Palatal bar pada RA dengan $\varnothing 0,8 \mathrm{~mm}$, f. Pir coffin pada RA dengan $\varnothing$ $0,9 \mathrm{~mm}$ dan sekrup ekspansi pada RB. Bionataor dibuat dengan bantuan tekniker lokal (gambar 1)

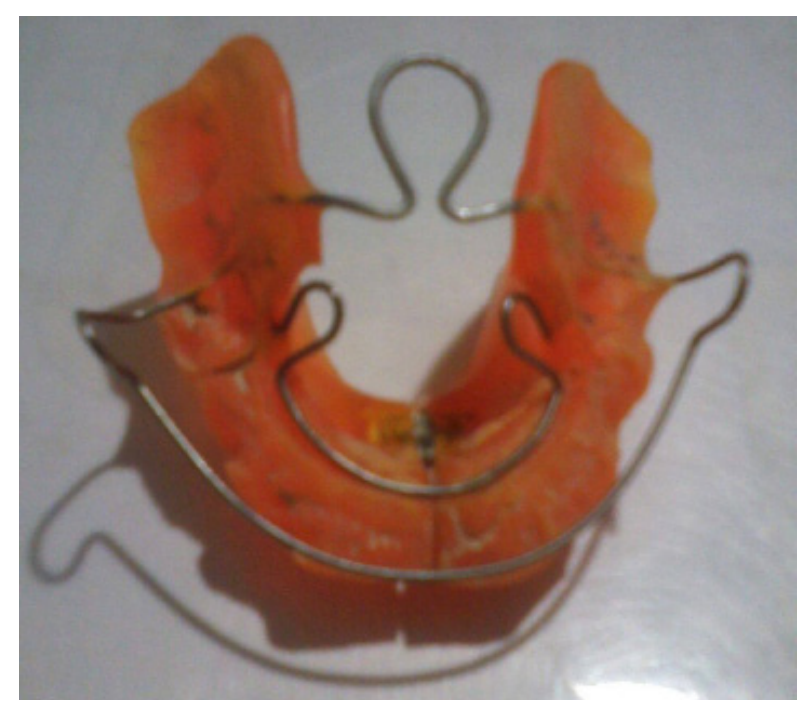

Gambar 1. Bionator yang dipakai oleh pasien 
Tabel 1. Analisis sefalometri sebelum dan sesudah perawatan 3 bulan

\begin{tabular}{lccc}
\hline Pengukuran & Nilai Normal & Sebelum Perawatan & Sesudah Perawatan 3 bulan \\
\hline Facial angle & $82^{\circ}-95^{\circ}$ & 81,5 & 85 \\
Angle of convexity & $-8,5^{\circ}-+9^{\circ}$ & +13 & $+5,5$ \\
Bidang A-B & $0-\left(-9^{\circ}\right)$ & -12 & $-4,5$ \\
FMPA & $17^{\circ}-28^{\circ}$ & 29 & 30 \\
Y- Axis & $53^{\circ}-66^{\circ}$ & 66 & 68 \\
SNA & $82^{\circ}$ & 82 & 84 \\
SNB & $80^{\circ}$ & 75 & 81,5 \\
ANB & $2^{\circ}$ & 7 & 3,5 \\
Bidang Mandibula -SN & $32^{\circ}$ & 34 & 32,5 \\
Inter I dan I & $130^{\circ}$ & 97 & 108 \\
Sudut I- NA & $22^{\circ}$ & 42,5 & 34 \\
I-NA (mm) & $4 m m$ & 13 & 9 \\
Sudut I-NB & $25^{\circ}$ & 33 & 34,5 \\
I- NB (mm) & $4 m m$ & 8 & 8 \\
IMPA & $81.5^{\circ}-97^{\circ}$ & 75,5 & 99 \\
FIS & $105^{\circ}-115^{\circ}$ & 129 & 123 \\
Bidang oklusal -SN & $14^{\circ}$ & 15 & 14 \\
Occl PI-FHP & $1,5^{\circ}-14,3^{\circ}$ & 11 & 10,5 \\
Overbite & $2-4 \mathrm{~mm}$ & 3,5 & 2 \\
Overjet & $2-4 \mathrm{~mm}$ & 11,5 & 5 \\
\hline
\end{tabular}

Pembuatan gigitan kerja, pasien diinstruksikan untuk menggigit malam dengan rahang bawah sudah dimajukan $2 \mathrm{~mm}$. Ketebalan malam pada anterior berkisar 2-4 $\mathrm{mm}$ sedangkan pada posterior 4-6 $\mathrm{mm}$. Median line segaris.

Bionator adalah alat untuk mengkoreksi gigitan melalui latihan otot pengunyahan. Alat ini didesain untuk memajukan mandibula secara langsung dan dengan pemakaian sepanjang hari, gigi lebih cepat bergerak, gigitan meningkat dan relasi molar menjadi normal. Bionator menggerakkan gigi menggunakan tekanan otot pengunyahan. Alat ini bekerja pada otot pengunyahan dengan cara: (1) menggigit-gigitkan gigi pada alat, (2) berbicara secara jelas, dan (3) tersenyum bersamaan dengan bibir Alat ini dilepaskan atau tidak digunakan hanya ketika makan dan minum, menyikat gigi atau membersihkan alat, dan sewaktu berolahraga. Pada minggu pertama, alat digunakan selama beberapa jam setiap harinya. Pada periode ini sangatlah bagus untuk berlatih berbicara ketika keadaan masih menggunakan alat di dalam mulut.
Pada minggu kedua, bionator digunakan selama aktivitas di dalam rumah. Selama minggu ketiga, alat digunakan ketika bersekolah dan selama di rumah. Terakhir pada minggu keempat, alat digunakan sepanjang hari dan ketika tidur.

Kontrol dilakukan seminggu sekali. Pada minggu pertama, belum dilakukan pengurangan plat akrilik dan penyesuaian gigitan dengan tujuan agar pasien beradaptasi dahulu dengan alat. Perawatan dengan alat ini dianggap selesai jika overjet $5 \mathrm{~mm}$ dan stabilitas dari temporomandibular joint tercapai. Setelah dilakukan perawatan myofungsional, dilakukan pencetakan model gigi sebagai panduan perencanaan tahapan perawatan dengan plat aktif. Selama kontrol, sekrup ekspansi dan coffin diaktifkan secara berkala, plat bagian oklusal, distal untuk gigi rahang atas, dan mesial untuk gigi rahang bawah dikurangi. Hal ini dilakukan untuk ekspansi $4 \mathrm{~mm}$ ke lateral sekaligus pencarian ruang untuk mengkoreksi malposisi gigi individual dan mencari kontak oklusi antara rahang atas dan bawah. Hasil perawatan setelah 3 bulan perawatan adalah profil 


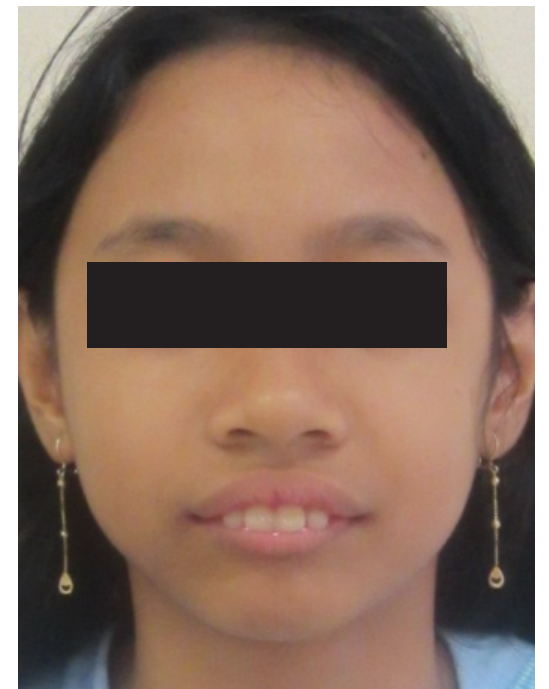

Gambar 2. Tampak depan sebelum perawatan

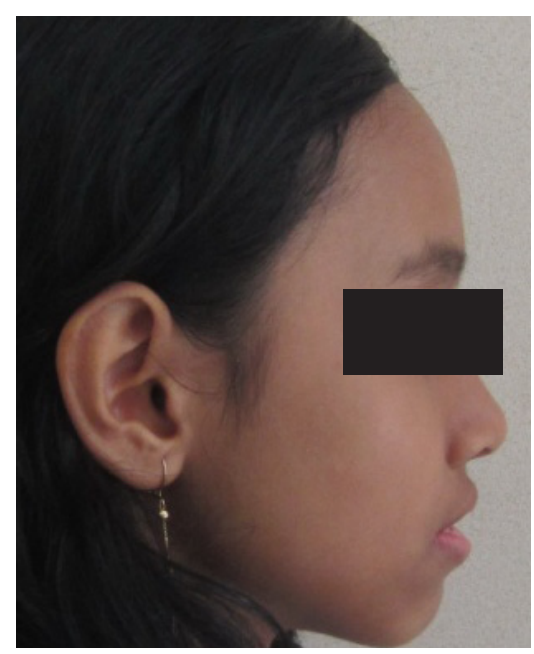

Gambar 5. Tampak samping sesudah perawatan

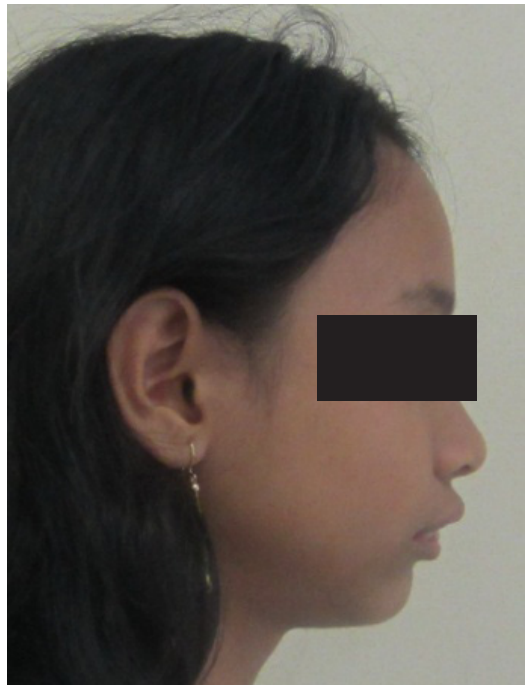

Gambar 3. Tampak samping sebelum perawatan

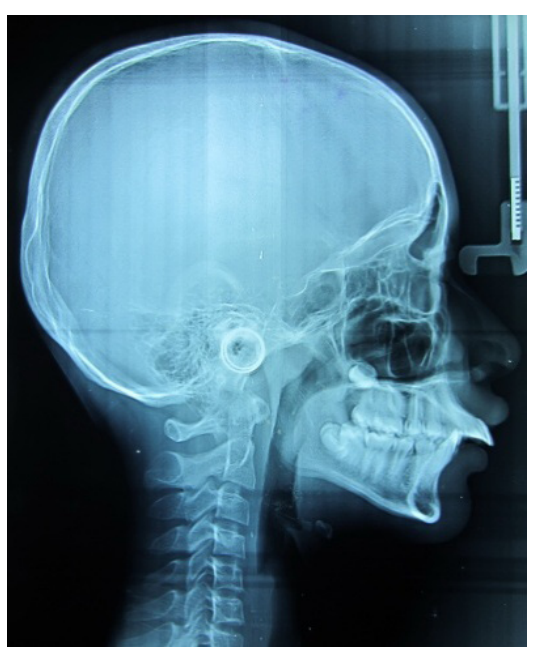

Gambar 6. Sefalometri sebelum perawatan

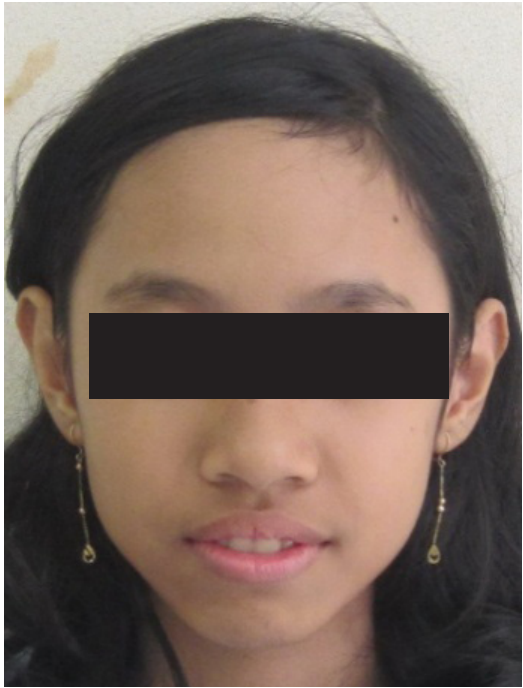

Gambar 4. Tampak depan sesudah perawatan

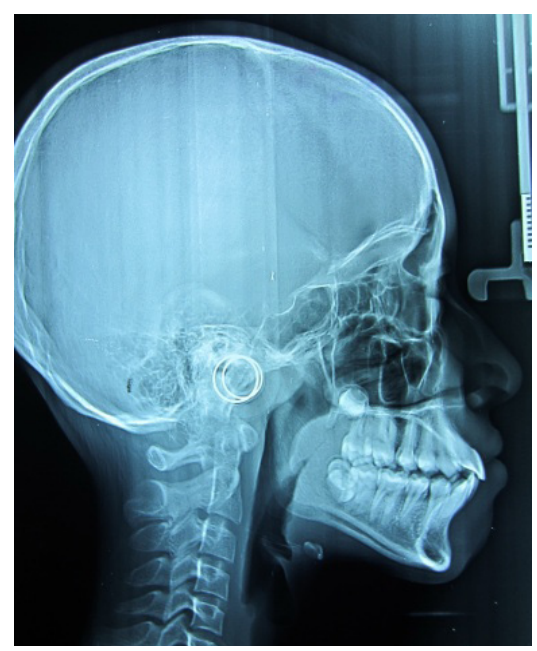

Gambar 7. Sefalometri sesudah perawatan pasien telah terkoreksi (pengukuran sefalometri dan model study) overjet berkurang, palatal bite hilang, dan openbite posterior. Kebiasaan buruk pasien juga telah hilang (sesuai pengakuan pasien dan orang tua)

\section{PEMBAHASAN}

Kasus Maloklusi Angle klas II divisi 1 dentoskeletal dengan retrusi mandibula dan bidental protrusif disertai dengan palatal bite, malposisi gigi individual, dengan kebiasaan buruk bernafas lewat mulut dan menggigit bibir bawah telah dirawat selama 3 bulan. Maloklusi Angle klas II divisi 1 tipe dentoskeletal disebabkan oleh faktor keturunan (ibu dan kakak dari ibu) dan diperparah dengan kebiasaaan buruk. Retrusi mandibula menyebabkan penampilan tidak estetis dan pasien merasa malu. Hasil dari pemeriksaan yang didukung dengan perhitungan-perhitungan dan faktor tumbuh kembang menunjukkan bahwa alat ortodontik yang digunakan bertujuan untuk menuntun rahang bawah untuk bergerak ke depan dan memperlebar lengkung rahang. Hasil sefalogram selama 3 bulan menunjukkan perubahan-perubahan yang cukup signifikan. Overjet menjadi $5 \mathrm{~mm}$, overbite menjadi 
$2 \mathrm{~mm}$, facial angle $85^{\circ}$, angle of convexity $+5,5^{\circ}$, sudut interinsisal $108^{\circ}$, SNA $84^{\circ}$, SNB $81,5^{\circ}$, dan ANB $3,5^{\circ}$ (Tabel).

\section{KESIMPULAN}

Maloklusi Klas II divisi 1 dentoskeletal pada masa pertumbuhan dan perkembangan dapat dirawat secara dini dengan menggunakan alat fungsional Bionator. Hasil perawatan cukup baik dengan terkoreksinya overjet dan perubahan profil muka pasien. Kerja sama, kesabaran dan motivasi yang tinggi antara operator, orang tua dan pasien diperlukan untuk menunjang keberhasilan perawatan ortodontik lepasan.

\section{DAFTAR PUSTAKA}

1. Malta L.A., Baccetti T., Franchi L., Faltin., dan McNamara J.A.: Long-Term Dentoskeletal Effect and facial Profile Changes Induce by Bionator Therapy, Angle Orthodontist 2010; 80(1): 10-17.

2. Faltin K., faltin R.M., Baccetti T., Franci L., Ghiozzi B., dan Mcnamara J.A.: Long-term Effectiveness and Treatment Timing for Bionator Therapy, Angle Orthodontist 2003; 73(3): 221-30.
3. Almaida M.R., Henriques J.F.C., Almeida R.R., Almeida-Pedrin R.R., Ursi W. : Treatment Effects Produced by The Bionator Appliance. Comparison with An Untreated Class II Sample, European Journal of Orthodontics 2004; 26: 65-72.

4. Almeida M.R., Henriques J.F.C., Ursi W. : Comparative Study of Frankel (FR-2) and Bionator Appliance in The Treatment of Class II Malocclusion, Am J Orthod Dentofac Orthop 2002; 121: 458-66

5. Bolmgren G.A., Moshiri F.: Bionator Treatment in Class II Division 1, Angle Orthod. 1986; 56: 255-62.

6. Mamadras A.H., Allen L.P. : Mandibular Response to Orthodontic Treatment with The Bionator Appliance, Am J Orthod Dentofac Orthop 1990; 97: 113-20.

7. Illing H.M., Morris D.O., Lee R.T. : AProspective Evaluation of Bass, Bionator, and Twin Block Appliances. Part I-The Hard Tissues. Eur $J$ Orthod, 1998; 20: 501-16

8. Bionator.com. Diakses dari http://www. bionator.com/why-the-bionator.php diunduh 5 Agustus 2013. 